\title{
Pilot Implementation of the Competence of Czech Paramedics to Administer Sufentanil for the Treatment of Pain in Acute Trauma Without Consulting a Physician: Observational Study
}

Metoděj RENZA ( $\square$ metodej.renza@seznam.cz)

Department of Anesthesia and Intensive Care, Third Faculty of Medicine, Charles University and FNKV University Hospital, Prague, Czech Republic

\section{Roman SYKORA}

Emergency Medical Services of Karlovy Vary region, Karlovy Vary, Czech Republic

\section{David PERAN}

Prague Emergency Medical Services

\section{Kristina HRICOVA}

Department of Nursing, Third Faculty of Medicine, Charles University in Prague, Czech Republic

\section{Nikola BRIZGALOVA}

Emergency Medical Services of Karlovy Vary region, Karlovy Vary, Czech Republic

\section{Petra BAKUROVA}

Emergency Medical Services of Karlovy Vary region, Karlovy Vary, Czech Republic

\section{Miloš KUKACKA}

Emergency Medical Services of Karlovy Vary region, Karlovy Vary, Czech Republic

\section{Research Article}

Keywords: Prehospital care, analgesia, sufentanil, paramedic, simulation, trauma

Posted Date: October 13th, 2021

DOl: https://doi.org/10.21203/rs.3.rs-955365/v1

License: (c) (1) This work is licensed under a Creative Commons Attribution 4.0 International License. Read Full License

Version of Record: A version of this preprint was published at BMC Emergency Medicine on April 9th, 2022. See the published version at https://doi.org/10.1186/s12873-022-00622-8. 


\section{Abstract}

\section{Background}

The use of intravenous opioids in the traumatic pain in pre-hospital care in the Czech Republic is based primarily on the indication of a physician. If the paramedic crew arrives at the site earlier or only on their own, analgesia is given after phone-call consultation with the physician or after his arrival at the site. The objective of this study was to evaluate the safety and efficacy of the indication and administration of sufentanil by paramedics in the treatment of pain in acute trauma adult patients without the physician's control.

\section{Methods}

Paramedics underwent voluntarily the simulation training aimed at administering intravenously sufentanil to treat pain in acute trauma in adults without physician's indication. Subsequently, the adverse events and efficacy were monitored for a six-month period and compared in two groups: administration of sufentanil by paramedics without this competence, who further consulted the administration by telephone with physicians (group Consultation) and those with this competence (group Competence).

\section{Results}

A total number of sufentanil administration in group Consultation was 88 and in group Competence 70 . There was no respiratory arrest, bradypnea, or need for oxygen therapy reported in any of the study groups. The incidence of nausea was the same $3 \%$ in Consultation; $(n=3)$ and in Competence $(n=2)$. Vomiting was not reported in the Consultation group and in $6 \%$ in the Competence group $(n=4)$. Intravenous antiemetic drugs were used in the Consultation group only in $1 \%(n=1)$ and in the Competence group in $7 \%$ of patients $(n=5)(p<0,05)$. In both groups there was observed a decrease in the numeric rating scale (Consultation: $M=-3,2 ; S D=1,2$ points vs. Competence: $M=-3,9 ; S D=1,8$ points).

\section{Conclusion}

Intravenous administration of sufentanil by properly trained paramedics without consultation with a physician in acute trauma can be considered safe.

\section{Background}

High quality and safe pain management is the goal of not only prehospital emergency care ${ }^{1}$ provided by emergency medical services (EMS) crews. In terms of competencies, systems of providing pre-hospital emergency care differ. In many European countries, also in the Czech pre-hospital emergency care, the system is historically dependent on physicians. ${ }^{2,3}$ Competencies of paramedics are based on specific legal norms and education of healthcare professionals and differs all around the world. ${ }^{4,5}$ Paramedic 
crews in the Czech Republic do not have the competency to administer analgesic medication without direct supervision of or without phone-call consultation with an EMS physician. ${ }^{6}$ It must be stated that shortage of physicians in the Czech EMS due to personnel and economic reasons leads to an increasing emphasis on the competencies of paramedics. However, the Czech system of healthcare legislation allows the employer or organization to delegate certain competencies to paramedics within completely standard procedure in a defined situation (also known as Standard Operating Protocol). Among the growing number of competencies of Czech paramedics there is still a need to treat acute pain in acute traumatic injuries with opioids in the case of less serious cases where no ambulance crew with physician is dispatched to the scene. ${ }^{7}$ At present, the absence of a physician in the ambulance crew on site leads to the need for a telephone consultation or a request for the arrival of a physician, which prolongs the time until effective analgesia and prolongs the patient's suffering. In addition, during and after the telephone consultation, the EMS physician is not present on the scene to address any complications.

\section{Objectives}

Primary objective of this study was to evaluate the safety and efficacy of indication and administration of the sufentanil in treatment of pain in acute trauma patients by paramedics without the physicians control.

\section{Methods}

Prior to the study a questionnaire survey focused on pain management in acute trauma among all paramedics of EMS of Karlovy Vary Region was conducted $(n=115$, return rate $81 \%(n=95))$. Based on main results of this survey the proposed competency to administer sufentanil by trained paramedics in acute trauma was identified as necessary for $80 \%(n=76)$ of paramedics. Subsequently, this competence was determined as voluntary. A total of 39 paramedics signed up and completed training program to administer sufentanil in acute trauma. The training consisted of theoretical e-learning part (14 days prior the training) and one training session (4 hours) based on medical simulations during August 2020. The training covered pharmacological and clinical information and specific indication criteria (case of acute traumatic pain without the presence of physician on site, adult patient, without impaired consciousness, hemodynamic stability) and also the training of detection and management of complications, with special emphasis on respiratory depression and bag mask ventilation was trained. The maximum possible fractionated intravenous dose was set to 20 micrograms of sufentanil. The final verification of the competence of paramedics was evaluated by 3 instructors (anesthesiologists working in EMS) during six simulation scenarios, hands-on station with bag mask ventilation and by final written exam focused on side effect, indications criteria and dose of sufentanil.

\section{Study design}

This was a single center, prospective, observational study with two monitored groups. The educational program, definition of competence and its implementation to internal standard of care was approved by 
the Medical Board of Emergency Medical Services of Karlovy Vary region on 22nd of May 2020. The study protocol and conduction of the study was approved by Ethical Committee of Emergency Medical Services of Karlovy Vary Region registered with State Institute for Drug Control of the Czech Republic on 11th of September 2020 under ref. no. ZN/78/ZZSKVK/20. Informed consent was not required from patients with acute trauma pain. It was carried out within the framework of tacit consent after standard information about the planned procedure within the provision of pre-hospital emergency care according to the Czech legislation ((Health Services Act No. 2011, 372 (CZ)). ${ }^{6}$ The protocol of the trial was retrospectively registered at clinicaltrials.com (NCT04913402).

\section{Study location}

The study was conducted at EMS of Karlovy Vary Region, Karlovy Vary, the Czech Republic during 6month period from 11th of September 2020 to 22nd of March 2021. A total number of 20.406 patients were treated during the study period by crews of EMS of Karlovy Vary Region.

\section{Participants and interventions}

All cases of administered sufentanil were checked from electronical patient documentation („ePaRe“ part MZD, European Medical Distribution Ltd., Bratislava, Slovak Republic). Subsequently, only events which met eligibility criteria were included in analysis. Eligibility criteria consist of: a) administration of sufentanil by paramedics on site without physical presence of physician in acute traumatic pain, b) adult patient (at least 18 years old), c) with no impairment of consciousness (defined as Alert and Glasgow Coma Scale $=15$ ), $d$ ) who is hemodynamically stable (defined by systolic blood pressure $>100 \mathrm{mmHg}$ and without presence of bradycardia bellow 60 beats per minute). The two study groups were identified from eligible cases of patients with pain in acute trauma, who were given sufentanil 1) by paramedics in a routine way, after telephone consultation with an EMS physician (Consultation) and 2) who were given sufentanil by competent paramedics themselves (Competency). In the Competency group, the paramedics were allowed to administer sufentanil intravenously up to 20 micrograms. The recommended Numeric Rating Scale (NRS) score for sufentanil administration consideration was above 4 points.

Baseline characteristics of both groups were obtained from electronical patient documentation: age, sex, NACA score (National Advisory Committee for Aeronautics), type of trauma (lower or upper limb, trauma of torso, head injury), dose of sufentanil and if there was fractional dose administration, and proportion of cases where additional non-opioid analgesia (paracetamol) was used.

\section{Outcome measures}

To measure the safety and efficacy of sufentanil administration information were extracted from electronical patient documentation. Incidence of respiratory arrest (the need for bag mask ventilation); bradypnea (less than 10 breaths per minute); or need for oxygen therapy (defined as decrease of $\mathrm{SpO}_{2}$ under 92 percent). Than the frequency of complete NRS reporting (before sufentanil administration and at the handover) were determined. Other adverse effect of sufentanil administration (incidence of nausea and vomiting and need for intravenous antiemetic drug - thiethylperazin) was evaluated. Moreover, the 
heart rate, blood pressure, $\mathrm{SpO}_{2}$ and respiratory rate before sufentanil administration and at the handover were noted.

\section{Statistical methods}

No sample size was calculated prior to the study but the period of half a year was set for evaluation. Due to the character of observations and predefined groups of paramedic with and without competency no randomization or blinding was used. Baseline characteristics and outcomes among study groups were tested by t-test for ordinal and Chi-square test for nominal variables. Statistical software STATISTICA 7.0 (StatSoft, Inc., Tulsa, Oklahoma, USA) was used for statistical analysis and calculations.

\section{Results}

The selection of eligible and description of excluded cases is presented in the flow diagram (Figure 1). A total number of sufentanil administered intravenously to patients with acute trauma by paramedics after phone call consultation with EMS physician (group Consultation) was 88 and by paramedics with competency without any consultation (group Competence) was 70.

The baseline characteristics of both groups including the spectrum of injuries and pharmacotherapy is in detail described in Table 1. The dose of intravenously administered sufentanil was almost identical in both groups (Consultation: $M=9.1 ; S D=2.0$ micrograms vs. Competence: $M=9.4 ; S D=2.4$ micrograms). 
Table 1

Baseline statistics

\begin{tabular}{|c|c|c|c|}
\hline & $\begin{array}{l}\text { CONSULTATION } \\
(\mathrm{n}=88)\end{array}$ & $\begin{array}{l}\text { COMPETENCE } \\
(n=70)\end{array}$ & \\
\hline Age (years) & $64,6(19,7)$ & $65,7(20,0)$ & NS \\
\hline Sex (women) & $61(69 \%)$ & $39(56 \%)$ & NS \\
\hline NACA & $2,5(0,5)$ & $2,4(0,5)$ & NS \\
\hline Trauma of lower limb & $57(65 \%)$ & $35(50 \%)$ & \multirow[t]{3}{*}{$N S^{1}$} \\
\hline Trauma of upper limb & $23(26 \%)$ & $22(31 \%)$ & \\
\hline Trauma of torso & $8(9 \%)$ & $13(19 \%)$ & \\
\hline Trauma of head & 0 & 0 & NS \\
\hline Dose of sufentanil $(\mu \mathrm{g})$ & $9,1(2,0)$ & $9,4(2,4)$ & NS \\
\hline Fractional administration & $24(27 \%)$ & $20(29 \%)$ & NS \\
\hline Additional non-opioid analgesia & $12(14 \%)$ & $10(13 \%)$ & NS \\
\hline
\end{tabular}

In terms of reporting the occurrence of adverse events (Table 2) there was no respiratory arrest or bradypnea reported in any of the study groups as well as the need for oxygen therapy after sufentanil administration. The incidence of nausea was the same in both groups: Consultation; $\mathrm{n}=3(3 \%)$ vs Competence, $\mathrm{n}=2(3 \%)$. Vomiting after sufentanil administration was not reported in the Consultation group and despite the incidence of vomiting in $6 \%$ in the Competence group $(n=4)$ this result did not reach statistical significance. Similarly, intravenous antiemetic drugs were used less frequently in the consultation group only in $1 \%(n=1)$ than in the Competence group in $7 \%$ of patients $(n=5)\left(\left(\chi^{2}(1, N\right.\right.$ $=158)=3,85, p<0,05)$. 
Table 2

Adverse events and its treatment after intravenous sufentanil administration in trauma

\begin{tabular}{|llll|}
\hline & $\begin{array}{l}\text { CONSULTATION } \\
(\mathbf{n}=\mathbf{8 8})\end{array}$ & $\begin{array}{l}\text { COMPETENCE } \\
(\mathbf{n}=70)\end{array}$ & NS \\
\hline Respiratory arrest & 0 & 0 & NS \\
\hline Bradypnea & 0 & 0 & \\
\hline Oxygen therapy after sufentanil administration & 0 & 0 & NS \\
\hline Nausea & $3(3 \%)$ & $2(3 \%)$ & NS \\
\hline Vomiting & 0 & $4(6 \%)$ & $\mathrm{P}<0,05$ \\
\hline Antiemetics administration & $1(1 \%)$ & $5(7 \%)$ & \\
\hline Data are presented as number and percentage. & & & \\
\hline
\end{tabular}

In both groups there was a decrease in the NRS (Consultation: $M=-3,2 ; S D=1,2$ points vs. Competence: $M=-3,9 ; S D=1,8$ points) without a statistically significant difference between groups: $\mathrm{t}(81)=-1,58 . \mathrm{p}=$ 0,059 . Complete NRS reporting was significantly more frequently reported in the Competency group in $86 \%(n=60)$ compared to $26 \%(n=23)$ in the Consultation group $\left(\chi^{2}(1, N=158)=47,35, p<0,0001\right)$. From such disproportionately reported data, a significant difference in the NRS was evident between Consultation $(M=-6,4 ; S D=1,5)$ and Competency group $(M=-7,9 ; S D=1,4): \mathrm{t}(81)=-4,05 . \mathrm{p}<0,05$ as presented in Table 3.

Table 3

Numeric rating scale (NRS) details

\begin{tabular}{|llll|}
\hline & $\begin{array}{l}\text { CONSULTATION } \\
(\mathbf{n}=\mathbf{8 8})\end{array}$ & $\begin{array}{l}\text { COMPETENCE } \\
(\mathbf{n}=\mathbf{7 0})\end{array}$ & $\mathrm{P}<0.05$ \\
\hline Complete report of NRS & $23(26 \%)$ & $60(86 \%)$ & $\mathrm{NS}$ \\
\hline NRS reduction (points) & $-3.2(1.2)$ & $-3.9(1.8)$ & $\mathrm{P}<0.05$ \\
\hline Initial NRS (points) & $6.4(1.5)$ & $7.9(1.4)$ & \\
\hline Data are presented as mean and standard deviation or as number and percentage.
\end{tabular}

There was not observed any significant effect of sufentanil administration on systolic and diastolic blood pressure, heart rate, peripheral oxygen saturation and respiratory rate and its differences in patients of both groups before administration of sufentanil and on handover (Table 4) and the values between both study groups did not differ significantly as well. 
Table 4

Effect of intravenous sufentanil administration in trauma on physiological parameters

\begin{tabular}{|c|c|c|c|c|c|}
\hline & \multicolumn{2}{|c|}{$\begin{array}{l}\text { CONSULTATION } \\
(\mathrm{n}=88)\end{array}$} & \multicolumn{2}{|c|}{$\begin{array}{l}\text { COMPETENCE } \\
(n=70)\end{array}$} & \\
\hline & On scene & Handover & On scene & Handover & \\
\hline Systolic blood pressure $(\mathrm{mmHg})$ & $\begin{array}{l}145.5 \\
(24.1)\end{array}$ & $\begin{array}{l}142.9 \\
(20.7)\end{array}$ & $\begin{array}{l}142.2 \\
(20.8)\end{array}$ & $\begin{array}{l}138.9 \\
(16.5)\end{array}$ & NS \\
\hline $\begin{array}{l}\text { Systolic blood pressure difference } \\
(\mathrm{mmHg})\end{array}$ & & $-2.7(13.2)$ & & $-3.3(11.2)$ & NS \\
\hline Diastolic blood pressure $(\mathrm{mmHg})$ & $\begin{array}{l}78.3 \\
(15.2)\end{array}$ & $\begin{array}{l}78.1 \\
(10.9)\end{array}$ & $\begin{array}{l}79.8 \\
(11.6)\end{array}$ & $\begin{array}{l}77.5 \\
(10.3)\end{array}$ & NS \\
\hline $\begin{array}{l}\text { Diastolic blood pressure difference } \\
(\mathrm{mmHg})\end{array}$ & & $-0.2(11.2)$ & & $-2.2(7.6)$ & NS \\
\hline $\begin{array}{l}\text { Heart rate } \\
(\mathrm{bpm})\end{array}$ & $\begin{array}{l}85.9 \\
(13.2)\end{array}$ & $\begin{array}{l}84.5 \\
(13.4)\end{array}$ & $\begin{array}{l}86.0 \\
(15.9)\end{array}$ & $\begin{array}{l}83.2 \\
(14.0)\end{array}$ & NS \\
\hline $\begin{array}{l}\text { Heart rate difference } \\
(\mathrm{bpm})^{1}\end{array}$ & & $-1.4(8.0)$ & & $-2.9(7.8)$ & NS \\
\hline SpO2 (\%) & $96.9(9.8)$ & $96.7(2.3)$ & $97.1(1.7)$ & $96.8(1.4)$ & NS \\
\hline SpO2 difference (\%) & & $-0.2(1.8)$ & & $-0.3(1.7)$ & NS \\
\hline Respiratory rate (breaths per minute) & $14.4(1.5)$ & $14.1(1.5)$ & $15.6(2.6)$ & $14.6(1.6)$ & NS \\
\hline $\begin{array}{l}\text { Respiratory rate difference } \\
\text { (breaths per minute) }\end{array}$ & & $-0.3(1.1)$ & & $-1.1(2.0)$ & NS \\
\hline
\end{tabular}

\section{Discussion}

This study focused on the creation of a new competence for paramedics in a physician based system of prehospital emergency care ${ }^{2}$, when paramedics usually do not have the competence to administer opioid analgesics. On the other hand, due to the urgency of emergency calls, paramedic crews are often sent to cases of less serious trauma on their own without a physician $\mathrm{crew}^{7}$, but these trauma patients are obviously in pain and paramedics should either call a physician on the scene or consult him for analgesia administration. From the available opioids in pre-hospital care provided in the Karlovy Vary region of the Czech Republic, the most frequently used opioid sufentanil was selected. Although sufentanil is a very potent opioid ${ }^{8}$ it has been confirmed by this study that when administered within a clearly defined indication and by well-trained paramedics, it is an effective and safe alternative to administration by 
telephone consultation with EMS physician. In addition, the authors believe that the paramedics training to solve complications after administration of sufentanil is beneficial not only for this independent competence, but it can also be used in other situations where the doctor prescribes by phone and is not present on the scene to solve possible complications.

In the results, there was recorded relatively few side effects, which is probably the result of strict indication criteria. Such a criteria were deliberately set very harshly to ensure that sufentanil was safe and that training was adequate.

Reducing the number of phone-call consultations with an EMS physician leads to a lower burden on paramedics and physicians. This study verified that it is possible to assign other competencies on the basis of simulation training with verification of knowledge and skills.

This single center observational study has several limitations. One of them is that new competence was given to paramedics who voluntary underwent training. This voluntariness could cause the bias of this study. Motivated paramedics have usually better performance than unmotivated. In addition, the analysis of the results was from a relatively short period of time when it was burdened with other special conditions, especially COVID-19 patients. Due to quarantine measures and reduced population movements, trauma in pre-hospital care has decreased.

It is certainly worth mentioning the difference in NRS reporting between groups. The study was conducted as a prospective observational study. The control group performed routine work (blinded) and only trained rescuers had to respect the new standard of care, which includes the obligation to report to the NRS when considering opioid administration ${ }^{9}$ based on new competence. This may partly explain the difference in complete NRS reporting before and after administration of sufentanil. Likewise, paramedics who should have consulted physicians may have a tendency to underestimate NRS and even monitor for side effects. This statement can be based on the lower need for administration of antiemetics in the control group. From these data it is possible to conclude that increasing the level of competencies of paramedics or education ${ }^{10}$ can lead to an increase in the quality of care provided thanks to a higher level of responsibility and motivation, which leads to more careful examination of patients, better focus on their needs and in the end also better medical documentation.

In general, the treatment of pain by opioids is still open area in emergency medicine and especially in the pre-hospital setting. ${ }^{11,12}$ This study focused on the administration of intravenous sufentanil in less severe traumatic injuries. So far it seems to be the first study addresses the use of intravenous sufentanil in acute trauma by paramedics without EMS physician consultation. Most studies focus on the administration of fentanyl or morphine ${ }^{13}$, ketamine $^{14,15}$, combination of fentanyl and ketamine ${ }^{16}$ or on another route of administration (e.g. intranasal or transmucosal). ${ }^{17,18,19}$ Our study does not address the use of opiates in children or other medical conditions (e.g. myocardial infarction) as it was presented in other studies. ${ }^{13,20}$ 
And at the same time, this study is in agreement with other studies from similar health care systems, and confirms that it is possible to entrust prehospital analgesia to trained paramedics. ${ }^{14}$

\section{Conclusion}

Intravenous administration of sufentanil by paramedics alone without consultation with a physician (in physician based healthcare systems) in acute adult trauma can be considered safe within the scope of trained and established competence and in compliance with the indication criteria.

\section{Abbreviations}

EMS - Emergency Medical Service

NACA - National Advisory Committee for Aeronautics

NRS - Numeric Rating Scale

\section{Declarations}

\section{Ethics approval and consent to participate}

The study protocol and conduction of the study was approved by Ethical Committee of Emergency Medical Services of Karlovy Vary Region registered with State Institute for Drug Control of the Czech Republic on $11^{\text {th }}$ of September 2020 under ref. no. ZN/78/ZZSKVK/20.

\section{Consent for publication}

Informed consent was not required from patients with acute trauma pain. It was carried out within the framework of tacit consent after standard information about the planned procedure within the provision of pre-hospital emergency care according to the Czech legislation ((Health Services Act No. 2011, 372 $(\mathrm{CZ}))^{6}$

\section{Consent for publication}

All authors have read gave to main author consent for publication this manuscript.

\section{Availability of data and material}

The datasets used and analysed during the current study are available from the corresponding author on reasonable request.

\section{Competing interests}

There are no competing interests of any author. 


\section{Funding}

No funding was obtained for this study. All research was part of organization operating costs.

\section{Authors' contributions}

M.R. and R.S. wrote the main manuscript and collect data.

K.H. and R.S. did the statistical analysis.

D.P. did revisions in the main manuscript.

M.K. P.B. N.B. did training for paramedics and comment on the main manuscript.

All authors reviewed the manuscript and agree with the submission.

\section{Acknowledgements}

Acknowledgement is focused on all participants who helped to improve paramedical system and reduce suffering of patients.

\section{References}

1. Visser E, Gosens T, Den Oudsten BL, De Vries J. The course, prediction, and treatment of acute and posttraumatic stress in trauma patients: A systematic review. J Trauma Acute Care Surg. 2017 Jun;82(6):1158-1183.

2. Seblova J, Cimpoesu D, Khoury A, Revue E, Trenkler S. Prehospital emergency care systems in Europe - EuSEM prehospital section survey 2016. Eur J Emerg Med. 2018 Dec;25(6):446-447.

3. Tintinalli JE, Cameron P, Holliman CJ, Mencl F, Puppala N. Historical Timeline of International Events. In: EMS: A Practical Global Guidebook. Shelton, Connecticut: People's Medical Publishing House USA, 2010, 19-37.

4. Timmermann A, Russo SG, Hollmann MW. Paramedic versus emergency physician emergency medical service: role of the anaesthesiologist and the European versus the Anglo-American concept. Curr Opin Anaesthesiol. 2008 Apr;21(2):222-7.

5. Wilson MH, Habig K, Wright C, Hughes A, Davies G, Imray CH. Pre-hospital emergency medicine. Lancet. 2015 Dec 19;386(10012):2526-34.

6. Decree No. 55/2011 Coll. Decree on the activities of medical staff and other professionals. Czech legislative.

7. Franěk O. Příjem tísňové výzvy [Handling of emergency call]. In: Manuál dispečera zdravotnického operačního středisko [The manual of the operator of the medical dispatching center]. Prague, Czech Republic: sine nomine, 2018, 84-126 (in czech) 
8. Scholz J, Steinfath M, Schulz M. Clinical pharmacokinetics of alfentanil, fentanyl and sufentanil. An update. Clin Pharmacokinet. 1996 Oct;31(4):275-92.

9. Scholten AC, Berben SA, Westmaas AH, van Grunsven PM, de Vaal ET, Rood PP, Hoogerwerf N, Doggen CJ, Schoonhoven L; Emergency Pain Study Group. Pain management in trauma patients in (pre)hospital based emergency care: current practice versus new guideline. Injury. 2015 May;46(5):798-806.

10. Smith A, Henning J. Identifying barriers to the administration of pre-hospital analgesia to adult trauma patients by UK paramedics: a qualitative interview study. Br Paramed J. 2019 Mar 1;3(4):4041.

11. Niemi-Murola L, Unkuri J, Hamunen K. Parenteral opioids in emergency medicine - A systematic review of efficacy and safety., Scand J Pain. 2011 Oct 1;2(4):187-194.

12. Yousefifard M, Askarian-Amiri S, Madani Neishaboori A, Sadeghi M, Saberian P, Baratloo A. Prehospital pain management; a systematic review of proposed guidelines. Arch Acad Emerg Med. 2019 Oct 6;7(1):e55.

13. Scharonow M, Alberding T, Oltmanns W, Weilbach C. Project for the introduction of prehospital analgesia with fentanyl and morphine administered by specially trained paramedics in a rural service area in Germany. J Pain Res. 2017 Nov 6;10:2595-2599.

14. Häske D, Schempf B, Gaier G, Niederberger C. Prähospitale Analgosedierung durch Rettungsassistenten: Effektivität und Prozessqualität unter ärztlicher Supervision [Prehospital analgesia performed by paramedics: quality in processes and effects under medical supervision]. Anaesthesist. 2014 Mar;63(3):209-16. German.

15. Losvik OK, Murad MK, Skjerve E, Husum H. Ketamine for prehospital trauma analgesia in a lowresource rural trauma system: a retrospective comparative study of ketamine and opioid analgesia in a ten-year cohort in Iraq. Scand J Trauma Resusc Emerg Med. 2015 Nov 9;23:94.

16. McMullan J, Droege C, Strilka R, Hart K, Lindsell C. Intranasal Ketamine as an Adjunct to Fentanyl for the Prehospital Treatment of Acute Traumatic Pain: Design and Rationale of a Randomized Controlled Trial. Prehosp Emerg Care. 2021 Jul-Aug;25(4):519-529.

17. Pietsch U, Berger Y, Schurter D, Theiler L, Wenzel V, Meuli L, Gr,ünenfelder A, Albrecht R. Nasal nalbuphine analgesia in prehospital trauma managed by first-responder personnel on ski slopes in Switzerland: an observational cohort study. Scand J Trauma Resusc Emerg Med. 2021 Feb 17;29(1):36.

18. Wedmore IS, Kotwal RS, McManus JG, Pennardt A, Talbot TS, Fowler M, McGhee L. Safety and efficacy of oral transmucosal fentanyl citrate for prehospital pain control on the battlefield. J Trauma Acute Care Surg. 2012 Dec;73(6 Suppl 5):S490-5.

19. Corrigan M, Wilson SS, Hampton J. Safety and efficacy of intranasally administered medications in the emergency department and prehospital settings. Am J Health Syst Pharm. 2015 Sep 15;72(18):1544-54. 
20. Browne LR, Studnek JR, Shah MI, Brousseau DC, Guse CE, Lerner EB. Prehospital Opioid Administration in the Emergency Care of Injured Children. Prehosp Emerg Care. 2016;20(1):59-65.

\section{Figures}

\section{Assessed for eligibility}

Intravenous sufentanil administration in analyzed period $(\mathrm{n}=346)$

Excluded due to physician on scene $(\mathrm{n}=144)$

\section{Enrollment}

Sufentanil administration by paramedics on site without physical presence of physician $(\mathrm{n}=203)$

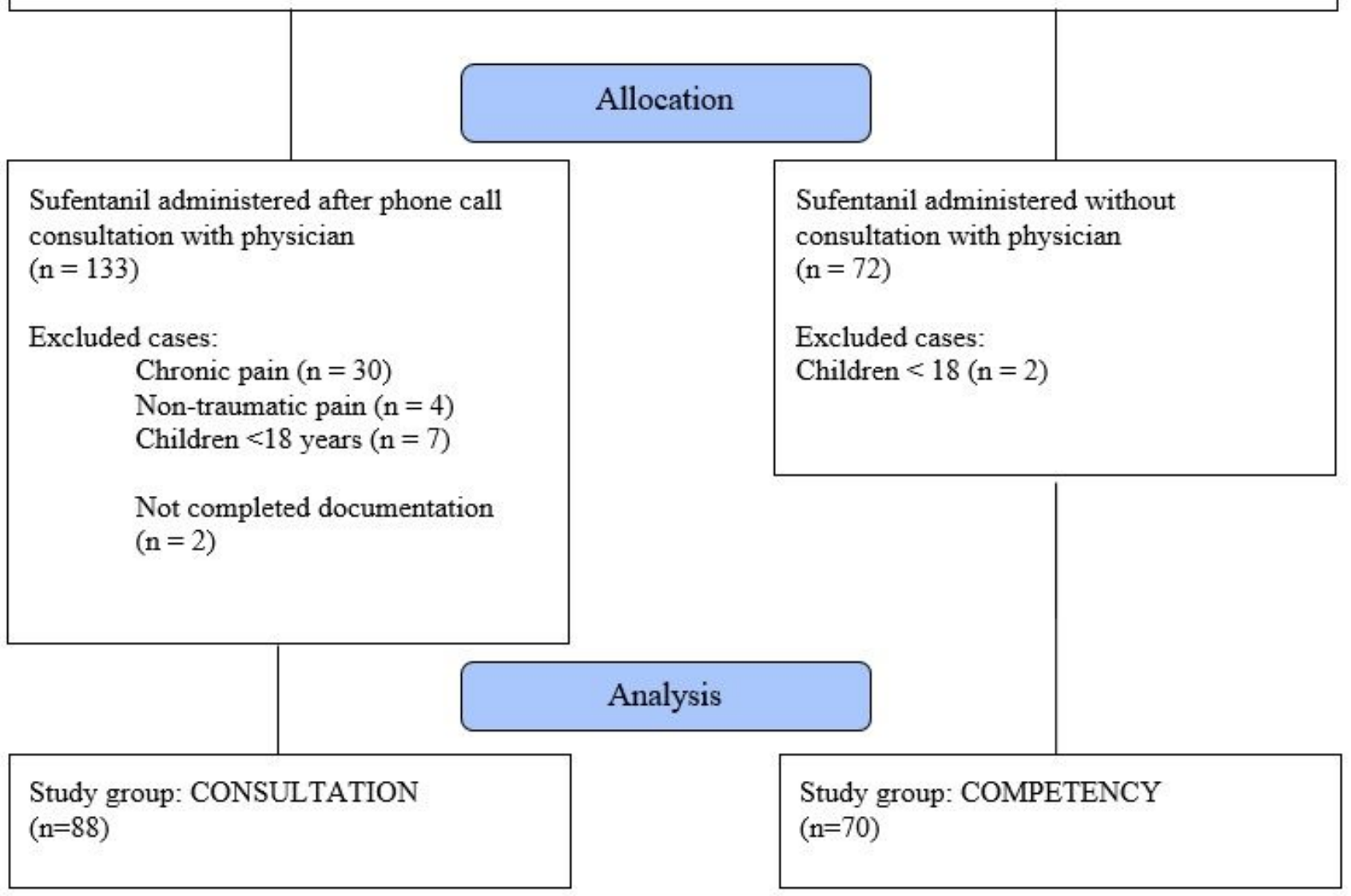


Flow diagram

Page 14/14 